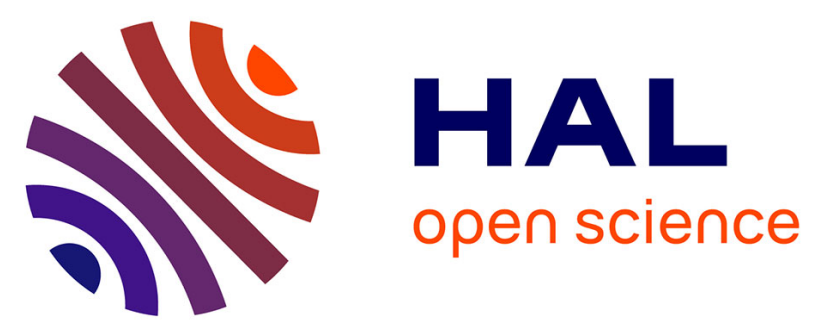

\title{
Elementary visuospatial perception deficit in children with neurodevelopmental disorders
}

\author{
Laure Pisella, Audrey Vialatte, Marie Martel, Myriam Prost-Lefebvre, \\ Clémence Caton, Mélanie Stalder, Rosa Yssad, Alice Catherine Roy, Carole \\ Vuillerot, Sibylle Gonzalez-Monge
}

\section{To cite this version:}

Laure Pisella, Audrey Vialatte, Marie Martel, Myriam Prost-Lefebvre, Clémence Caton, et al.. Elementary visuospatial perception deficit in children with neurodevelopmental disorders. developmental medecine and child neurology, 2021, 63 (4), pp.457-464. hal-03008937

\section{HAL Id: hal-03008937 \\ https://hal.science/hal-03008937}

Submitted on 17 Nov 2020

HAL is a multi-disciplinary open access archive for the deposit and dissemination of scientific research documents, whether they are published or not. The documents may come from teaching and research institutions in France or abroad, or from public or private research centers.
L'archive ouverte pluridisciplinaire HAL, est destinée au dépôt et à la diffusion de documents scientifiques de niveau recherche, publiés ou non, émanant des établissements d'enseignement et de recherche français ou étrangers, des laboratoires publics ou privés. 
[Original article: 2 tables; 3 figures, 1 online figure]

Elementary visuospatial perception deficit in children with

neurodevelopmental disorders

LAURE PISELLA ${ }^{1}$

AUDREY VIALATTE ${ }^{1}$

MARIE MARTEL ${ }^{2}$

MYRIAM PROST-LEFEBVRE ${ }^{3}$

CLÉMENCE CATON ${ }^{1}$

MÉLANIE STALDER ${ }^{1}$

ROSA YSSAD ${ }^{1}$

ALICE C ROY ${ }^{2}$

CAROLE VUILLEROT ${ }^{4}$

SIBYLLE GONZALEZ-MONGE ${ }^{4}$

1 Centre de Recherche en Neurosciences de Lyon (CRNL), University de Lyon, Bron; 2 Laboratoire Dynamique du Langage, University de Lyon, Lyon; 3 Hospices Civils de Lyon, Service de NeuroOphtalmologie, Bron; 4 Hospices Civils de Lyon, Hôpital Femme-Mère-Enfant, Service de Rééducation Pédiatrique, Bron, France.

Correspondence to Laure Pisella, Centre de Recherche en Neurosciences de Lyon (CRNL), Inserm U1028, CNRS UMR 5292, University de Lyon, Bron, France. E-mail: laure.pisella@inserm.fr

\section{PUBLICATION DATA}


Accepted for publication 00th Month 2020.

Published online 00th Month 2020.

\section{ABBREVIATIONS}

DCD Developmental coordination disorder

EVSP Elementary visuospatial perception

SLD Specific learning disorder

[Abstract]

AIM To assess the prevalence of elementary visuospatial perception (EVSP) deficit in neurodevelopmental disorders in children.

METHOD Using a screening test designed and validated to measure dorsal EVSP ability, 168 children diagnosed with developmental coordination disorder (DCD), specific learning disorder (SLD), attention-deficit/hyperactivity disorder (ADHD), and/or oral language disorder were compared with a group of 184 typically developing children. We also tested 14 children with binocular vision dysfunction and no neurodevelopmental disorder.

RESULTS Children with SLD scored below the interquartile range of typically developing children as frequently (59\%) as children with DCD, but only $5 \%$ were severely impaired (i.e. scored as outliers). Children with DCD were the most severely impaired (22\% of outliers), even more so when they exhibited a co-occuring disorder. Children with language disorder and those with binocular vision dysfunction scored similarly to the group of typically developing children. 
INTERPRETATION These results confirm the importance of assessing EVSP in the clinical evaluation of children with neurodevelopmental disorder, in particular those presenting with DCD or SLD.

[First page footer]

(C) Mac Keith Press 2020

DOI: $10.1111 / \mathrm{dmcn} . x x x x x$

[Left page footer]

Developmental Medicine \& Child Neurology 2020, 62: 000-000

[Right page footer]

Visuospatial Deficit in Developmental Disorders Laure Pisella et al.

[Boxed text on page 2]

\section{What this paper adds}

- More than fifty percent of children with developmental coordination disorder (DCD) scored below the normal interquartile range on the elementary visuospatial perception (EVSP) test.

- More than fifty percent of children with specific learning disorder (SLD) scored below the normal interquartile range on the EVSP test.

- Twenty-two percent of children with DCD performed as outliers in visuospatial perceptual comparison tasks.

- Children with language disorder and those with binocular vision dysfunction scored similarly to typically developing children. 
[Main text]

Elementary visuospatial perception (EVSP) involves distinguishing, through vision, the relative position of objects in the environment, as well as their spatial metrics (size, length, and angle). It consists of collecting, overtly or covertly, different 'snapshots' in multiple reference frames and integrating them as an accurate conscious representation of surrounding space. Therefore, it implies spatial working memory processes. ${ }^{1}$ EVSP is usually evaluated in clinical paediatric routine using a combination of multiple and sometimes non-specific tests. Therefore, we designed and validated a screening test lasting only 15 minutes and involving no motor manual response, visual gnosia, or language..$^{2,3}$

EVSP is 'elementary' in the sense that it contributes to the development of other cognitive and visuomotor functions; however, it overpasses the primary visual areas and relies on the middle occipital gyri (occipital score) and the posterior parietal cortex (parietal score) pertaining to the dorsal visual stream (see, in Pisella et al., ${ }^{2}$ the impaired performance of two patients with occipito-parietal damage as well as the full literature subserving this claim; see also reviews ${ }^{1,4,5}$ challenging the dual stream theory that postulates that the dorsal visual stream is not involved in conscious visual perception). Atkinson and Braddick ${ }^{6}$ have proposed a 'dorsalstream vulnerability' in many conditions of abnormal human development in relation to spatial cognition, attention, and planning of actions.

Meta-analyses have identified visuospatial processing as a major deficit in the population with developmental coordination disorder (DCD), ${ }^{7,8}$ whether visuospatial processing is assessed with or without temporal constraint, by motor or perceptual tasks (e.g. graphic copying skills, visuoconstructional skills such as Block design, or 
tests of visual discrimination with responses selected among multiple choice, sometimes with superimposed shapes). In particular, children with DCD have been shown to be less proficient than typically developing children in discriminating shape, area, slope, pattern, line length, and size constancy. ${ }^{9,10}$ They performed poorly even when the motor component of the visual task was removed. ${ }^{11-19}$ The literature has also reported deficits of EVSP in specific learning disorder (SLD), especially in dyslexia $^{20-22}$ and dyscalculia. ${ }^{22-25}$

In this prospective study, we used our validated screening test ${ }^{3}$ to evaluate the prevalence of EVSP deficits in 168 children presenting with four categories of neurodevelopmental disorders defined by the the Diagnostic and Statistical Manual of Mental Disorders, Fifth Edition (DSM-5): DCD, SLD, oral language disorder, and/or attention-deficit/hyperactivity disorder (ADHD). Their performance at the EVSP screening test was compared with a population of 184 typically developing children. On the basis of the literature, we expected to find EVSP deficits in children with DCD or SLD but not in children with language disorder. We also tested a comparison group of 14 children with binocular vision dysfunction and no neurodevelopmental disorder to confirm that our screening test targets impairments of cortical visual processing and not of stereopsis, eye alignment, or oculomotor function.

\section{METHOD}

\section{Participants}

As illustrated in the flowchart (Fig. S1, online supporting information), 497 individuals in total were enrolled in this prospective study of the EVSP screening test. In the present analysis, we excluded a total of 131 individuals who were adult, were born 
preterm, or presented with cerebral palsy, epilepsy, autistic spectrum disorders, or intellectual disability. We ended up with a final database of 366 children whose carers gave their informed written consent for the EVSP screening test. Clinical recruitment was done with approval of the Research Ethic Boards of the University Hospital of Lyon (CPP Sud-Est II, number 2015-54-2) among children coming for out-patient consultation (at the rehabilitation unit Delta01 of the OVE Foundation, at the orthoptist, or at the paediatric rehabilitation unit of the Hospices Civils de Lyon for a potential diagnosis of neurodevelopmental disorder). Typically developing children and several children with neurodevelopmental disorders also came from research recruitment (CPP Sud-Est II, n²009-036-AM3-2). The final database included 184 typically developing children; 14 children with no developmental disorder but presenting impaired binocular vision due to oculomotor, stereopsis, and/or eye alignment dysfunction; and 168 children diagnosed with DCD, SLD, language disorder, and/or ADHD. The diagnoses were established by an interdisciplinary clinical team as defined by DSM-5. ${ }^{26}$

\section{The EVSP screening test}

The EVSP screening test ${ }^{2}$ aims to test EVSP in isolation, namely without involving any complex language, motor, and gnosic function. It comprises six subtests (T1, T2, T3, T4, T5, T6; see Fig. 1), each composed of 12 trials of increasing difficulty. A score of maximum 12 correct answers was computed for each subtest as well as a total score of maximum 72 correct answers. On the basis of the neural substrates found in the literature ${ }^{27-30}$ (see Pisella et al. $^{2}$ for a full account) and on the performance of two patients with slightly different occipito-parietal damage, Pisella et

al. $^{2}$ also proposed computing two composite scores. The 'occipital' score was the 
sum of the scores at $\mathrm{T} 1$ and $\mathrm{T} 2$, the two subtests requiring magnitude comparison (with a maximum of 24 correct answers), while the 'parietal' score was the sum of the scores at T3, T4, T5, and T6, the four tests requiring spatial integration between an object and a landmark (with a maximum of 48 correct answers).

\section{Testing conditions}

The children were comfortably seated in front of a table on which the visual stimuli were presented in turn on cardboard sheets without any time constraints. Each subtest began with two easy training trials for which the experimenter gave the correct responses. The entire test was expected to last no more than 15 minutes, even for young children and those with neurodevelopmental disorder.

\section{Scoring}

For each participant, using the 12 binary responses for each trial ('correct' vs 'incorrect'), we first computed the score for each subtest (range 0-12) as well as the total score (best performance: $12 \times 6=72$ ) and the 'occipital' and 'parietal' composite scores (best performance: $2 \times 12=24$ and $4 \times 12=48$ respectively). ${ }^{2}$

The scores of individuals from the typically developing group were used to compute the mean and the median (M), the lower and higher limits of the interquartile range (IQR; named Q1 and Q3 respectively) and the lower and higher outlier limits (OL_sup=Q3+[1.5 $\times \mathrm{IQR}]$; OL_inf=Q1-[1.5 $\times \mathrm{IQR}])$ of the normative distributions for each age category. ${ }^{3}$ 


\section{Statistical analysis}

Statistics were analysed using Statistica software in 2019 on a database collected over 9 years. To do statistical analyses with all data independently of age category, the raw scores of individuals were compared with the normative limits of their age category and converted into six scoring classes along the schematic representing the box-and-whiskers as presented in Figure 2.

\section{Prevalence}

To evaluate the prevalence of EVSP deficit in each clinical group, we computed the number of individuals in this group who performed with a score inferior to the lower outlier limit of the scoring distribution of typically developing children of their age category (class 1) and transformed the number into an observed percentage of severely impaired children among a given clinical population. We then performed a statistical comparison of this observed percentage with the percentage of $5 \%$ (corresponding to the theoretical percentage of scoring in class 1 in the group of typically developing children on the basis of the definition of the lower outlier limit limit) using an alternative to the $\chi^{2}$ test for low samples: Fisher's exact test. To specifically test whether the distribution of individuals scoring below the outlier limit was significantly higher than normal in a given group, we used a one-sided statistical comparison.

To test statistically whether the occurrence of low EVSP scores was important in a given clinical group, we also computed the number of individuals in this group who performed with a score inferior to the IQR (Q1) of the scoring distribution of typically developing children of their age category. This number included children 
scoring in classes 1 or 2 and was also transformed into a percentage that was statistically compared with the percentage of $25 \%$ (corresponding to the theoretical percentage of scoring below Q1 in the group of typically developing children on the basis of the definition of the lower IQR limit Q1 using Fisher's exact test). To test whether the distribution of individuals scoring below Q1 was significantly higher than normal in a given group, we used a one-sided statistical comparison. The significance threshold was fixed at $5 \%$.

\section{Statistical comparison of EVSP between groups}

Given that the EVSP scores increase significantly with age $e^{2,3}$ and that our database included children with a large and various age distribution (Fig. S1), we could not perform analysis of variance (ANOVA) and post hoc tests between groups directly comparing the raw total scores. Instead, we were able to undertake Kruskal-Wallis one-way ANOVA and multiple bilateral Mann-Whitney $U$ tests corrected for false detection rate to compare the mean class of total scoring between clinical groups, and separately for the occipital and parietal scores.

\section{RESULTS}

\section{Description of the non-typically developing children population}

The age distribution, sex ratio, and percentage of children needing assistance or specialized schooling observed for each category of clinical diagnosis are presented in Table 1.

The sex ratio of our sample is representative of a population of non-typically developing children with a larger percentage of males for all clinical categories of the 
DSM-5 (about two males for one female on average, which corresponds to $66 \%$ being males).

\section{Prevalence of EVSP deficit in clinical groups}

Table 2 presents the number of individuals assessed in each clinical group, and the number of individuals scoring below the lower limit of the IQR of their age category $(<Q 1$, classes 1 and 2; see Fig. 3), and the number of those among them scoring below the outlier limit (class 1).

A total of 97 children with DCD were enrolled in this prospective study. Among them, 36 presented DCD without comorbidity. Among these children with DCD only, $58 \%$ presented a score below the lower quartile (Q1) of their age category (this percentage is significantly different to $25 \%, p<0.01$ ) and $22 \%$ presented a clear pathological performance, scoring below the outlier limit of their age category $(p<0.01)$. In individuals with DCD and at least one other co-occuring neurodevelopmental disorder, over 57\% presented scores below Q1 and over 26\% presented scores below the outlier limit, except when DCD was only associated with SLD. In the 'multidys' group (defined as presenting with DCD and two or three additional neurodevelopmental disorders), 77\% had scores below Q1 $(p<0.01)$ and $43 \%$ had scores below the outlier limit $(p<0.01)$. The presence of DCD is thus specifically associated with a high percentage of pathological performance at the EVSP screening test (below the outlier limit of the same age category).

In the group with SLD only, 59\% had scores below Q1 $(p<0.01)$. Nevertheless, in contrast to DCD, the scores of SLD children remained above the outlier limit of the typically developing children of the same age category (only $5 \%$ of scores below the outlier limit, $p=0.25)$. 
In our small group of children with ADHD only, 57\% scored below Q1 and only two $(14 \%)$ scored as outliers, both percentages did not reach significance $(p=0.11$ and $p=0.23$ respectively).

In the group of 20 children presenting with isolated oral language disorder, only four (20\%) scored below Q1 of their age category, which did not differ from the distribution of the population of typically developing children $(p=0.48)$. The group of 14 children with no neurodevelopmental disorder but impaired binocular vision constituted another 'control' group, with two children (14\%) scoring as outliers and only five (36\%) scoring below Q1 of their age category. These scores did not differ from the distribution of the population of typically developing children ( $p=0.54$ and $p=0.23$ respectively).

\section{Statistical comparison of EVSP total and subscores between clinical groups}

As illustrated in Figure 3a, the Kruskal-Wallis one-way ANOVA performed on the median class score showed a significant effect of the clinical group $\left(H_{7,167}=20.2\right.$; $p<0.01)$. Multiple bilateral Mann-Whitney $U$ tests showed that both DCD and multidys groups were statistically different to the group with language disorder (language disorder vs DCD: $z=3.22 ; p<0.05$; language disorder vs multidys: $z=3.86$; $p<0.01$ ) and there was no difference between SLD and other groups (all $z<2.78$; $p>0.05)$.

As illustrated in Figure 3b,c, this significantly lower performance of the groups of children with DCD and multidys at the EVSP test was mainly driven by the lower 'parietal score'. Indeed, the Kruskal-Wallis one-way ANOVAs showed a highly significant effect of the group on the parietal score $\left(H_{7,167}=19.6 ; p<0.01\right)$ but no significant effect of the group on the occipital score $\left(H_{7,167}=9.8 ; p=0.20\right)$. Multiple 
bilateral Mann-Whitney $U$ tests showed that both DCD and multidys groups were statistically different from the group with language disorder for the parietal score (language disorder vs DCD: $z=3.34 ; p<0.05$; language disorder vs multidys: $z=3.81$; $p<0.01$ ), but not for the occipital score (language disorder vs DCD: $z=1.36 ; p>0.05$; language disorder vs multidys: $z=2.49 ; p>0.05)$. The comparison between language disorder and SLD groups did not reach significance (parietal score: $z=2.80 ; p>0.05$; occipital score: $z=1.43 ; p>0.05)$.

\section{DISCUSSION}

The EVSP screening test is an easy and fast, but nevertheless specific, way to evaluate conscious visuospatial processing ability in children. ${ }^{2,3}$ This test has been designed to measure the two-dimensional visuospatial perceptual abilities of the dorsal stream of cortical visual processing, which have to be distinguished from 'peripheral' visual function. Indeed, the two patients with occipito-parietal damage showing a clear impairment on the EVSP screening test ${ }^{2}$ had neither visual acuity and binocular vision nor eye alignment and oculomotor dysfunction after the damage to their central nervous system. Also, our group of children with binocular vision dysfunction and no neurodevelopmental disorder did not score significantly differently than the typically developing population at the EVSP screening test.

In this study, we used the EVSP screening test to evaluate the prevalence of dorsal-stream visuospatial processing deficits in non-typically developing children. Our sample of non-typically developing children comprised 22\% with SLD, 21\% with DCD, $12 \%$ with language disorder, $8 \%$ with $A D H D$, and $36 \%$ with at least two comorbidities. Our sample thus reflected the French population of children with neurodevelopmental disorders since about $40 \%$ of them present comorbidities 
(https://www.inserm.fr/information-en-sante/dossiers-information/troubles-

specifiques-apprentissages), with the most frequent comorbidities being DCD with language disorder, DCD with ADHD, and DCD with SLD. The mean age and sex ratio of each clinical category in our sample (Table 1) was also representative of what is reported for their mean age of diagnosis in the French population (http://www.ffdys.com/wp-

content/uploads/2016/11/FFDYS SYNTHESE Enquete 2015-

parcours de sante.pdf), since the oral language develops earlier, language disorder is diagnosed the earliest, followed by DCD and SLD, and then ADHD which is often diagnosed later than 10 years of age in France. Our sample also reflected the French population for the frequency of each clinical category: the French 'Fédération des Dys' reports that in the total population of schoolchildren, SLD is the most frequent (about $4 \%$ for developmental dyscalculia and/or dyslexia), followed by DCD $(3 \%)$, and then language disorder (2\%). The reported prevalence of ADHD is between 3\% and 5\% (https://www.has-sante.fr/jcms/c 2025618/fr/trouble-deficit-de-lattention-avec-ou-sans-hyperactivite-tdah-reperer-la-souffrance-accompagner-lenfant-et-la-famille-questions-/-reponses), which fits our sample if we consider our population of ADHD only combined with our population presenting with AHHD as a comorbidity (98\% of children with ADHD have reported a comorbidity in the 2015 survey of the French 'Fédération des Dys': http://www.ffdys.com/wpcontent/uploads/2016/11/FFDYS SYNTHESE Enquete 2015parcours de sante.pdf).

In the present study, we excluded potential causes of brain injury that might lead to cerebral visual impairment (see our exclusion criteria in Fig. S1). Nevertheless, the prevalence of low scoring at the EVSP screening test was high in 
our population of 168 non-typically developing children, with more than half scoring below the lower quartile limit (Q1) and 17\% scoring as outliers. If we consider children in this population who exhibited more than two comorbidities (multidys group), an even larger percentage (77\%) scored below Q1 and 43\% scored below the outlier limit. Many of these children with neurodevelopmental disorders thus displayed a developmental dysfunction of the dorsal visual stream of unknown origin.

Importantly, the prevalence of dorsal-stream visuospatial processing deficits was different between the clinical categories as defined by the DSM-5. On the one hand, the low prevalence of EVSP deficit in children with oral language disorder supports divergent construct validity for our screening test. On the other hand, the significantly high prevalence of EVSP deficit in children with SLD only (59\%) and DCD only (58\%) was also expected from the literature, as further developed below.

In the group of children with SLD, $54 \%$ scored like the worst $25 \%$ of typically developing children (between Q1 and the lower outlier limit) and only 5\% scored as outliers of their age category. This high prevalence of low scoring in children with SLD is in accordance with the correlation of the EVSP screening test with the arithmetic subtest and the Working Memory Index of the Wechsler Intelligence Scale for Children, Fourth Edition. ${ }^{3}$ It suggests an important contribution of EVSP deficit to developmental dyscalculia, probably through inability to use visuospatial imagery as a support for logico-mathematical reasoning. ${ }^{31}$ The EVSP screening test score has been found not to correlate with reading age, ${ }^{3}$ probably because of the large heterogeneity of profiles between the children with dyslexia. Future investigations should evaluate whether low EVSP scores are observed more specifically in children with dyslexia exhibiting visual confusions of letters, and whether it correlates with the visuoattentional letter span. ${ }^{32}$ 
The severity of the deficit was higher in the group of children with DCD, with more than $20 \%$ exhibiting scores below the lower outlier limit of their age category. This severity explains why, when comparing the performance between clinical groups (Fig. 3), only the mean score of the DCD group (not of the SLD group) was significantly lower than the group with language disorder. The high prevalence of EVSP deficit in children with DCD, with or without comorbidities, is consistent with the correlation of the EVSP screening test, ${ }^{3}$ with tests of visuoconstructive abilities (Block test ${ }^{33}$ ) and tests evaluating manual dexterity under visual control such as the Purdue pegboard ${ }^{34}$ and the manual dexterity tasks of the Movement Assessment Battery for Children. ${ }^{35}$ However, the EVSP score correlated neither with the other subscores of the Movement Assessment Battery nor with its total score used to diagnose DCD, suggesting that different aspects of DCD are being assessed by these different subscores. Children with DCD can have a pathological total score on the Movement Assessment Battery with heterogenous profiles.

In the EVSP screening test, children with DCD exhibiting outlier scores were more precisely impaired on the 'parietal' subscore (Fig. 3). The sum of the subtests T3, T4, T5, and T6 constituting the 'parietal' score provides an accumulation of evidence of a deficit in 'landmark relative positioning ability' ('where' function ${ }^{27}$ ). The usefulness of the two other subtests ( $\mathrm{T} 1$ and $\mathrm{T} 2$ ) is not clear from the present study since no group of neurodevelopmental disorders statistically differed from the group with language disorder on this 'occipital' subscore evaluating 'magnitude processing' (length and size). Further investigations in clinical categories not included in the present study might show impaired performance at this 'occipital' subscore, for example in children born preterm and/or with cerebral palsy at risk of cerebral visual impairment. 
The EVSP screening test could thus be used to refine the diagnosis within the traditional categories of neurodevelopmental disorders and to provide more specific indications for rehabilitation. If the EVSP test is being used as a screening test that will be completed by further assessments, then it should have a minimum of false negatives, hence scoring below Q1 would seem to be a suitable detection threshold for children who could benefit from a specific EVSP rehabilitation.

Reflecting the age at which neurodevelopmental disorders are clinically diagnosed, the distribution of our non-typically developing group across age categories was uneven and particularly poor between 4 and 6 years old. This constitutes one limitation of our study because we would advise using our screening test as soon as possible to detect children at risk of developmental disorder and start them on early specific EVSP rehabilitation. Another limitation could be that children recruited at hospitals tend to have more severe and complex deficits. However, our additional research recruitment allowed us to test children more representative of the population with SLD and DCD and ensured the generability of the present results.

In conclusion, the EVSP screening test seems to be a useful tool to pinpoint those children who exhibit a visuospatial perceptual deficit among the heterogenous groups with DCD or SLD. In these numerous children, the hypothesis that the EVSP deficit may contribute in varying degrees to their dexterity, reading, or logicomathematical performance should be considered for their rehabilitation.

\section{ACKNOWLEDGEMENTS}

The authors wish to thank David Chatelus for his participation in data collection. The authors have stated they had no interests that might be perceived as posing a conflict or bias. 


\section{Supporting information}

The additional material may be found online:

Figure S1: Flowchart of the present study involving the assessment of children using the EVSP screening test.

\section{REFERENCES}

1. Pisella L. Visual perception is dependent on visuospatial working memory and thus on the posterior parietal cortex. Ann Phys Rehabil Med 2017; 60: 141-7.

2. Pisella $L$, André $V$, Gavault $E$, et al. A test revealing the slow acquisition and the dorsal stream substrate of visuo-spatial perception. Neuropsychologia 2013; 51: $106-13$.

3. Pisella L, Martel M, Roy AC, Vuillerot C, Gonzalez-Monge S. Validation of a simple screening test for elementary visuo-spatial perception deficit. Ann Phys Rehabil Med 2020; 63: 302-8.

4. Pisella L, Sergio L, Blangero A, Torchin H, Vighetto A, Rossetti Y. Optic ataxia and the function of the dorsal stream: contributions to perception and action. Neuropsychologia 2009; 47: 3033-44.

5. Rossetti $\mathrm{Y}$, Pisella $\mathrm{L}$, Mclntosh RD. Rise and fall of the two visual systems theory. Ann Phys Rehabil Med. 2017; 60: 130-40.

6. Atkinson $\mathrm{J}$, Braddick O. From genes to brain development to phenotypic behavior: "dorsal-stream vulnerability" in relation to spatial cognition, attention, and planning of actions in Williams syndrome (WS) and other developmental disorders. Prog Brain Res 2011; 189: 261-83. 
7. Wilson $\mathrm{PH}$, McKenzie BE. Information processing deficits associated with developmental coordination disorder: a meta-analysis of research findings. $J$ Child Psychol Psychiatry 1998; 39: 829-40.

8. Wilson $\mathrm{PH}$, Ruddock $\mathrm{S}$, Smits-Engelsman $\mathrm{B}$, Polatajko $\mathrm{H}$, Blank R. Understanding performance deficits in developmental coordination disorder: a meta-analysis of recent research. Dev Med Child Neurol 2013; 55: 217-28.

9. Henderson SE, Barnett A, Henderson L. Visuospatial difficulties and clumsiness: on the interpretation of conjoined deficits. J Child Psychol Psychiatry 1994; 35: $961-9$.

10. Hulme C, Lord R. Clumsy children - a review of recent research. Child Care Health Dev 1986; 12: 257-69.

11. Jarus $T$, Lourie-Gelberg $Y$, Engel-Yeger $B$, Bart $O$. Participation patterns of school-aged children with and without DCD. Res Dev Disabil 2011; 32: 1323-31.

12. Loh PR, Piek JP, Barrett NC. Comorbid ADHD and DCD: examining cognitive functions using the WISC-IV. Res Dev Disabil 2011; 32: 1260-9.

13. Crawford SG, Dewey D. Co-occurring disorders: a possible key to visual perceptual deficits in children with developmental coordination disorder? Hum Mov Sci 2008; 27: 154-69.

14. Tsai CL, Wu SK. Relationship of visual perceptual deficit and motor impairment in children with developmental coordination disorder. Percept Mot Skills 2008; 107: 457-72.

15. Tsai CL, Wilson PH, Wu SK. Role of visual-perceptual skills (non-motor) in children with developmental coordination disorder. Hum Mov Sci 2008; 27: 64964. 
16. Van Waelvelde H, De Weerdt W, De Cock P, Smits-Engelsman BC. Association between visual perceptual deficits and motor deficits in children with developmental coordination disorder. Dev Med Child Neurol 2004; 46: 661-6.

17. Schoemaker MM, van der Wees M, Flapper B, Verheij-Jansen N, ScholtenJaegers S, Geuze RH. Perceptual skills of children with developmental coordination disorder. Hum Mov Sci 2001; 20: 111-33.

18. Parush S, Yochman A, Cohen D, Gershon E. Relation of visual perception and visual-motor integration for clumsy children. Percept Mot Skills 1998; 86: 291-5.

19. Fletcher-Flinn C, Elmes H, Strugnell D. Visual-perceptual and phonological factors in the acquisition of literacy among children with congenital developmental coordination disorder. Dev Med Child Neurol 1997; 39: 158-66.

20. Winner E, von Karolyi C, Malinsky D, et al. Dyslexia and visual-spatial talents: Compensation vs deficit model. Brain Lang 2001; 76: 81-110.

21. Von Karolyi C, Winner E, Gray W, Sherman GF. Dyslexia linked to talent: global visual-spatial ability. Brain Lang 2003; 85: 427-31.

22. Oszwa U. Mathematical, linguistic and visuospatial skills in Polish children with specific learning disabilities in reading and arithmetic. Acta Neuropsychologica 2006; 4: 286-95.

23. Szucs D, Devine A, Soltesz F, Nobes A, Gabriel F. Developmental dyscalculia is related to visuo-spatial memory and inhibition impairment. Cortex 2013; 49: 2674-88.

24. Bugden S, Ansari D. Probing the nature of deficits in the 'Approximate Number System' in children with persistent developmental dyscalculia. Dev Sci 2016; 19: 817-33. 
25. McCaskey U, von Aster M, O'Gorman Tuura R, Kucian K. Adolescents with developmental dyscalculia do not have a generalized magnitude deficit processing of discrete and continuous magnitudes. Front Hum Neurosci 2017; 20: 102.

26. American Psychiatric Association. Diagnostic and Statistical Manual of Mental Disorders (5th edition). Arlington, VA: American Psychiatric Association, 2013.

27. Ungerleider LG, Mishkin M (1982) Two cortical visual systems. In: Ingle DJ, Goodale MA, Mansfield RJW (editors). Analysis of visual behavior. Cambridge, MA: MIT Press: 549-86.

28. Faillenot I, Decety J, Jeannerod $M$. Human brain activity related to the perception of spatial features of objects. Neuroimage 1999; 10: 114-24.

29. Mclntosh RD, Pritchard CL, Dijkerman HC, Milner AD, Roberts RC. Prehension and perception of size in left visual neglect. Behav Neurol 2001; 13: 3-15.

30. Fink GR, Marshall JC, Shah NJ, et al. Line bisection judgments implicate right parietal cortex and cerebellum as assessed by fMRI. Neurology 2000; 54: 132431.

31. Mathieu R, Epinat-Duclos J, Sigovan M, et al. What's behind a "+" sign? Perceiving an arithmetic operator recruits brain circuits for spatial orienting. Cereb Cortex 2017; 14: 1-12.

32. Bosse M-L, Tainturier MJ, Valdois S. Developmental dyslexia: The visual attention span deficit hypothesis. Cognition 2007; 104: 198-230.

33. Wechsler D. Echelle d'Intelligence deWechsler pour enfants et adolescents quatrième édition (WISC IV). Paris: Les Editions du Centre de Psychologie Appliquée, 2005. 
34. Tiffin J, Asher El. The Purdue Pegboard: norms and studies of reliability and validity. J Appl Psychol 1948; 32: 234-47.

35. Soppelsa R, Albaret JM. Manuel de la Batterie d'Évaluation du Mouvement chez l'Enfant. Paris: Les Éditions du Centre de Psychologie Appliquée, 2004. 
Table 1: Demographic information per clinical group

\begin{tabular}{lclll}
\hline Clinical groups & $n$ & $\begin{array}{l}\text { Mean age } \\
\text { (range), y:mo }\end{array}$ & $\begin{array}{l}\text { Males } \\
(\%)\end{array}$ & $\begin{array}{l}\text { Schooling (\% of children } \\
\text { needing assistance or } \\
\text { specialized schooling) }\end{array}$ \\
\hline DCD & 36 & $10: 8(7: 5-16: 4)$ & 77 & 65 \\
SLD & 37 & $10: 1(7: 6-15: 8)$ & 65 & 13 \\
Oral language disorder & 20 & $8: 5(4: 8-11: 10)$ & 65 & 56 \\
ADHD & 14 & $10: 10(7: 6-16: 2)$ & 64 & 25 \\
DCD+ADHD & 11 & $9: 8(6: 5-15: 0)$ & 73 & 33 \\
DCD+SLD & 13 & $10: 2(7: 4-15: 11)$ & 61 & 23 \\
$\begin{array}{l}\text { DCD+language disorder } \\
\text { Multidys (DCD+more }\end{array}$ & 23 & $9: 10(5: 11-15: 6)$ & 87 & 78 \\
than one comorbidity) & $9: 10(6: 1-12: 4)$ & 85 & 77 \\
$\begin{array}{l}\text { Children with binocular } \\
\text { vision dysfunction but no } \\
\text { developmental disorder }\end{array}$ & 14 & $9: 0(6: 1-16: 5)$ & 57 & 0 \\
\hline $\begin{array}{l}\text { DCD, developmental coordination disorder; SLD, specific learning disorder; ADHD, } \\
\text { attention-deficit/hyperactivity disorder. }\end{array}$ &
\end{tabular}


Table 2: Prevalence of elementary visuospatial perception deficit in clinical groups

\begin{tabular}{|c|c|c|}
\hline Groups & $\begin{array}{l}n(\%) \text { of individuals } \\
\text { with a total score } \\
\text { below Q1 of the same } \\
\text { age category }\end{array}$ & $\begin{array}{l}n(\%) \text { of individuals } \\
\text { with a total score } \\
\text { below the outlier limit } \\
\text { of the same age } \\
\text { category }\end{array}$ \\
\hline $\mathrm{DCD}$ & $21(58)^{\mathrm{a}}$ & $8(22)^{a}$ \\
\hline SLD & $22(59)^{a}$ & $2(5)$ \\
\hline Language disorder & $4(20)$ & 0 \\
\hline ADHD & $8(57)$ & $2(14)$ \\
\hline $\mathrm{DCD}+\mathrm{ADHD}$ & $8(73)^{b}$ & $4(36)^{b}$ \\
\hline DCD+SLD & $7(54)$ & $1(8)$ \\
\hline DCD+language disorder & $13(57)^{\mathrm{a}}$ & $6(26)^{b}$ \\
\hline $\begin{array}{l}\text { Multidys (DCD+more } \\
\text { than one comorbidity) }\end{array}$ & $10(77)^{\mathrm{a}}$ & $6(43)^{a}$ \\
\hline $\begin{array}{l}\text { Total } \\
\text { neurodevelopmental } \\
\text { disorders }\end{array}$ & $93(55)^{\mathrm{a}}$ & $29(17)^{a}$ \\
\hline $\begin{array}{l}\text { Children with binocular } \\
\text { vision dysfunction but no } \\
\text { developmental disorder }\end{array}$ & $5(36)$ & $2(14)$ \\
\hline \multicolumn{3}{|c|}{$\begin{array}{l}\text { The groups comprised } 36 \text { individuals with developmental coordination disorder } \\
\text { (DCD), } 37 \text { with specific learning disorder (SLD), } 20 \text { with oral language disorder, } 14 \\
\text { with attention-deficit/hyperactivity disorder (ADHD), } 11 \text { combining DCD and ADHD, } \\
13 \text { combining DCD and SLD, } 23 \text { combining DCD and language disorder, and } 14 \\
\text { combining DCD and more than one comorbidity. The prevalence is also displayed for } \\
\text { the total group of } 168 \text { children presenting with neurodevelopemental disorders and } \\
\text { for the group of } 14 \text { children with binocular vision dysfunction but no developmental } \\
\text { disorder. }{ }^{a} p<0.01 ;{ }^{b} p<0.05 \text {. }\end{array}$} \\
\hline
\end{tabular}




\section{[Figure legends]}

Figure 1: Examples of perceptual comparisons required in each of the six subtests of the elementary visuospatial perception (EVSP) screening test.

Figure 2: Method of scoring independent of age. The table on the right shows that the raw scores obtained by an individual at the elementary visuospatial perception (EVSP) screening test $(x)$ were compared with the distribution of the typically developing population of the same age category and converted into six class scores. The distribution of typically developing children is schematized as a box-and-whisker plot in the left panel: the $25 \%$ of typically developing children scoring the highest are above the higher quartile limit (Q3), the $25 \%$ of typically developing children scoring the lowest are below the lower quartile limit (Q1), the $50 \%$ of the typically developing population lies in-between, i.e. in the interquartile range represented by the box. The median (M) is included within this box, and the outlier limits are represented by the whiskers (inferior and superior outlier limits: OL_inf and OL_sup respectively).

Figure 3: (a) Elementary visuospatial perception (EVSP) minimal and maximal class score (whiskers), median (horizontal line), and interquartile range (box) in the different clinical categories of developmental disorder: developmental coordination disorder (DCD); specific learning disorder (SLD); attention-deficit/hyperactivity disorder (ADHD); oral language disorder (LD). Significant Mann-Whitney $U$ test comparisons between groups are mentioned $\left({ }^{*} p<0.05,{ }^{* *} p<0.01\right)$. (b) Same boxwhisker graph and statistics for the 'occipital' sub_score (sum of T1 and T2). (c) Same box-and-whisker graph and statistics for the 'parietal' sub_score (sum of T3, $\mathrm{T} 4, \mathrm{~T} 5$, and T6). 